\title{
REPLY \\ Discourses on sexual pleasure after genital modifications: the fallacy of genital determinism (a response to J. Steven Svoboda)
}

\author{
Sara Johnsdotter \\ Faculty of Health and Society, Malmö University, Sweden \\ sara.johnsdotter@mah.se
}

This is a reply to:

Svoboda, J. Steven 2013. "Promoting genital autonomy by exploring commonalities between male, female, intersex, and cosmetic female genital cutting." Global Discourse.

http://dx.doi.org/10.1080/23269995.2013.804757.

\section{Introduction}

In his compelling paper, 'Promoting Genital Autonomy by Exploring Commonalities Between Male, Female, Intersex, and Cosmetic Female Genital Cutting', J. Steven Svoboda (2013) explores commonalities between various forms of genital modifications and shows how the West responds inconsistently from a human rights perspective, failing to grant every child the same right to a genital integrity. Svoboda arrives at the conclusion that circumcision of male infants on religious or traditional grounds ought, like female circumcision, to be legally banned. Such a juxtaposition between female and male genital cuttings ${ }^{1}$ could also lead to the conclusion that societies ought to make (certain forms of) female genital alterations in girls lawful, as has been put forth by the American anthropologist Richard A. Shweder $(2002,2013)$. Irrespective of the stance, such analysis of commonalities between different forms of genital modifications - taking gender or ethnic equity as a starting point - is a fruitful approach to uncovering cultural blind spots. This is particularly productive when surgery in intersexed children is included in the analysis, as Svoboda demonstrates.

In his article, Svoboda touches upon sexual effects of genital modifications, and I would like to take the opportunity to elaborate on this question. This is not a critique of Svoboda's views. He is critical of the 'medicalized model of women's sexuality' and in an earlier co-authored paper (Darby and Svoboda 2007) it is emphasized that 'sexual pleasure is a highly subjective response, and it is difficult to arrive at quantitative data on this issue' (310). Yet I would like to discuss these issues in some more detail, since it seems to be in this field - genital modifications and sexual pleasure - that some of the future disputes will unfold.

My argument is that there are no scientific truths about sexual pleasure after genital modifications - only cultural constructions disguised as a medical science. Also, I intend to demonstrate with a few examples how these medical statements about effects on sexual pleasure are associated with politics. I conclude by arguing that current discussions on the sexual effects of genital modifications are reductionist due to widespread assumptions about the role of genitalia in sexuality what might be characterized as 'genital determinism'.

\section{Discourses on sexual effects of genital modifications}

Effects on ability to feel sexual pleasure after genital modifications have been discussed in all the contexts presented by Svoboda: in relation to circumcision of boys and girls, surgery of intersexed children and cosmetic genital surgery in adult women. Cosmetic genital surgery in women includes, for example, removal or reduction of the inner labia, vaginal tightening, liposuction of the mons veneris (fatty tissue over the pubic bone - these are performed in order to create a sense of proportion when the inner labia have been shortened), clitoral reduction and clitoral repositioning (see e.g. Braun 2005; Renganathan, Cartwright, and Cardozo 2009; Kelly and Foster 2012). These modifications are often framed in positive terms, as a means of improving the sexual pleasure. 
Australian gender scholar Virginia Braun concludes after a media analysis and interviews with surgeons:

While impeded sexual possibilities and pleasures were central in media and surgeon accounts of why women might choose to have [female genital cosmetic surgery], increased sexual pleasure as an outcome of surgery was the main area in which sexual pleasure was discussed.

(Braun 2005, 412; emphasis in original)

A case recently debated concerns a 33-year-old British woman who went through clitoridectomy for aesthetic reasons, with the physicians involved in the case testifying that her sexual life, including her scores for sexual satisfaction, was enhanced after the surgery; 'Her libido and sexual relationship with her husband had significantly improved' (Veale and Daniels 2012, 728; the case debated in later issues of the journal, Archives of Sexual Behavior).

In contrast, medical statements - made by both activists opposing 'female genital mutilation' and medical scholars - about negative effects on sexual pleasure after female circumcision are a commonplace. A statement by obstetricians:

The operation destroys much or all of the vulvar nerve endings, and seems likely to delay or prevent arousal and subsequent orgasm. [...] Even the mildest form of circumcision removes the part of a woman's body containing nerves of vital importance to sexual pleasure and fulfillment. (Elchalal et al. 1997, 106)

This is in line with the public discourse on 'female genital mutilation' where there is a widespread assumption that female circumcision is detrimental to the ability to enjoy sex (noted by e.g. Darby and Svoboda 2007; Dustin 2010; Johnsdotter and Essén 2010; Wade 2012). In reality, no research supports such assumptions, and studies show that differences in sexual function between cut and uncut women are small or non-existent (for overviews, see e.g. Obermeyer 2005; Berg and Denison 2012).

Yet another example of medical statements, which undermines what we can expect after having been informed in the discourse on 'female genital mutilation' about alleged destroyed ability to feel sexual pleasure, concerns descriptions of sexual function after surgery on intersexed children. In earlier texts on clitoriplasty in intersexed children, amputation and clitoridectomy are discussed rather prosaically, as in this case by a couple of American urologists:

It is evident from reviewing the literature and from our experience that the size of the hypertrophied clitoris is the major factor in deciding whether to amputate or relocate it. If a large clitoris is recessed or relocated, it is possible for the patient to present with a turgid and painful mass during sexual excitation in later life. Hence, total clitoridectomy would be the procedure of choice in this situation. (Ansell and Rajfer 1981, 683)

In their view, 'any procedure that is utilized in the surgical reconstruction of the patient with ambiguous genitalia should create normal-appearing and functional external genitalia' $(1981,681)$. In recent years, surgeons are no longer so confident. For example, the British surgeon C.R.J. Woodhouse observes in a medical article that:

All the evidence shows the great importance of the clitoris in achieving orgasm. After vaginal reconstruction about half of women will be able to achieve orgasm, but almost always with clitoral stimulation. With a natural vagina treated by regular dilatation all women can achieve orgasm, but if the clitoris has been amputated only $71 \%$ can do so. (Woodhouse 2004, 58, my emphasis)

Obviously, after decades of clitoral amputation in intersexed children in the West (see e.g. Karkazis 2008), the initial expectation seems to be that amputation of the clitoris did not affect ability to orgasm. It appears that attitudes toward clitoral surgery in children diagnosed with DSD (Disorders of Sex Development) are undergoing drastic changes - Woodhouse continues the paragraph above by saying, 'This emphasizes the need to preserve the clitoris' (2004, 58; see also e.g. Maharaj et al. 2005; Hughes et al. 2006; discussing later recommendations to be careful with clitoral tissue in intersex surgery). ${ }^{2}$ 
But the quote above shows the drastically different starting points when it comes to depicting the role of the clitoris in, on the one hand, a medical discourse on (western) children that go through clitoral modifications within the scope of biomedicine and, on the other hand, those who go through it in the context of African cultural traditions. ${ }^{3}$

There seems to be no objective or value-free mode of describing the sexual function of the various parts of female genitalia. Similar conflicting views present themselves when it comes to the male genitalia after modification. While the common view is that the foreskin of the penis is 'just a flap of skin' (critically quoted by ethicist Evans 2011, 442) and that its removal has no negative effects on sexual function (e.g. Morris, Waskett, and Gray 2012; Krieger et al. 2008), other researchers advocate the opposite view and describe the foreskin as the most sensitive part of the penis (Darby and Svoboda 2007; Johnson 2010; Bronselaer et al. 2013). Darby and Svoboda argue that the widespread comparison of the penile glans to the clitoral glans (leading to conclusions such as 'the mildest form, clitoridectomy, is anatomically equivalent to amputation of the penis', Toubia 1994, 712) is erroneous and that the correct analogy in physiological terms would be foreskin-clitoris (Darby and Svoboda 2007, 309-310).

\section{Sexual pleasure after genital modifications - a vexed issue in academia}

Two academic battles concerning sexual pleasure are currently taking place in the research fields of male and female circumcisions. The background is described by Svoboda (2013) in his article: there is a general acceptance of male circumcision in western contexts, while all forms of female circumcision are banned and frequently labelled barbarian. As aptly observed by Darby and Svoboda, 'we now find the WHO conducting two quite separate research projects: one to find evidence for the harm of [female circumcision], another to find evidence for the benefits of [male circumcision]' $(2007,312)$.

Regarding female circumcision and sexual pleasure, there has for a long time been a void of reliable studies to support widespread assumptions about lost ability to enjoy sex as a result of genital modification. In a review of available studies in 2005, Carla Makhlouf Obermeyer concluded that 'Concerning sexuality, most of the existing studies suffer from conceptual and methodological shortcomings, and the available evidence does not support the hypotheses that circumcision destroys sexual function or precludes enjoyment of sexual relations' $(2005,443)$. Since this publication in 2005, no metaanalysis was conducted until the Norwegian quantitative public health researcher Berg and colleagues (2010) published their report in 2010.

Unfortunately, out of the fifteen studies in their survey, only two were deemed to be of high quality. Ten of the fifteen studies were deemed by Berg et al. themselves to be of 'low quality', a fact that did not prevent them from extrapolating results from them. The authors admit to the limitations associated with an analysis of studies of such low quality, but insist in their conclusions about reduced sexual satisfaction and desire $(2010,6){ }^{4}$ A correlation worth noting in the literature on the health effects of female genital cutting is that the higher the quality of the study, the more likely it is that no statistically significant difference will be found between circumcised and uncircumcised women (e.g. Obermeyer 2005).

The political impetus to exaggerate negative effects on sexuality after female circumcision was recently criticized by a group of academicians in a policy advisory published by the Hastings Centre Report, 'Seven Things to Know About Female Genital Surgeries in Africa' (The Public Policy Advisory Network on Female Genital Surgeries in Africa, 2012; I was one of fifteen co-signatories). Among other things, we stated that 'a high percentage of women who have had genital surgery have rich sexual lives, including desire, arousal, orgasm and satisfaction, and their frequency of sexual activity is not reduced' (22), which is in accordance not only with studies deemed to be of good quality but also, actually, with the data in the Berg et al. survey.

In a commentary, the American gynaecologist Nawal Nour objected to this statement, claiming that 'high percentage' ought to have been changed to 'some.' She found the summary of sexual effects in the advisory 'implausible' and implied it was exaggerated (Nour 2012, 31). Dr. Nour supported her objection by referring to the metaanalysis conducted by Berg and colleagues. Indeed, the Berg et al. survey seems to fill this void experienced by activists searching for arguments to justify a condemnation of 'female genital mutilation'. The survey, disregarding the risks involved in 'garbage 
in, garbage out' calculations, ends in conclusions that sound reliable - and alarming. The WHO, key actor in this field, embraces this meta-analysis and reproduces the results and conclusions without any reservations as to the quality of the studies included:

Sexual problems are also more common among women who have undergone FGM. They are 1.5 times more likely to experience pain during sexual intercourse, have significantly less sexual satisfaction and are twice as likely to report a lack of sexual desire. (reference to Berg et al. 2010; WHO 2012, 3)

In contrast, the given point of departure as to male circumcision is generally that such a modification does not affect men's ability to enjoy sex in any negative way. Using the search string 'circumcision sexuality pleasure' in the WHO publications database, ${ }^{5}$ the only hit concerning effects on sexual pleasure after male circumcision is in a manual for performing circumcision, including suggestions on how to raise some issues in education about reproductive health and male circumcision:

Do any of you have any questions or concerns about male circumcision? I [a hypothetical instructor] know that there are many myths about male circumcision that circulate. For example, some people think that circumcision can cause impotence (failure of erection) or reduce sexual pleasure. Others think that circumcision will cure impotence. Let me assure you that none of these is true. (WHO, UNAIDS, and JHPIEGO 2009, 38)

In 2011 a group of Danish epidemiologists published an article in International Journal of Epidemiology based on data from a national health survey in Denmark, showing an association between male circumcision and frequent orgasm difficulties, and also pointing to female partners of circumcised men having an increased risk of not feeling sexually fulfilled (Frisch et al. 2011).6 In a letter to the editor in a later issue, Morris, Waskett, and Gray (2012) criticised the study and the conclusions drawn. In a response to this critique, Frisch defended their research and seized the opportunity to disclose some intrigue going on behind the scenes: Morris had been one of the reviewers of the submitted manuscript, and during the peer review process he had alarmed his peer group through an email list, encouraging people to send critical letters to the editors of the journal (Frisch 2012). Besides demonstrating a specific academic's ardent commitment and work methods, the conflict possibly reflects how contentious the issue of sexual pleasure in relation to a male circumcision is. ${ }^{7}$

As the American anthropologist Kirsten Bell (2005) has so convincingly argued (her work is also discussed by Svoboda), the descriptions of negative or positive effects with regard to sexual pleasure of female and male circumcision have everything to do with how we construct sexuality in the first place. Notions about (too) strong a male libido will result in conclusions that the male circumcision and reduced sensitivity are advantageous (examples given by Frisch 2011, 1377), while there will be assumptions that '[a] woman's sexual instincts, being fundamentally more delicate, will be crippled by any form of genital surgery' (Bell 2005, 136). Investigating the constructions of sexuality in other cultural contexts and relating them to notions of effects on sexuality after circumcision in those places may be illuminating. For example, anthropologist Maria Malmström (2009) has discussed, after fieldwork in Cairo, how the male libido is seen as weaker than its female counterpart. Female circumcision is not expected to erase the possibility to feel sexual pleasure or orgasm (and many women talk about sexual pleasure), but is regarded as a means to equalize that difference and create a balance (Malmström 2009).

\section{Culture and sexual pleasure: the fallacy of genital determinism}

After reviewing the literature on sexual pleasure after male and female circumcisions, is it possible to draw any general conclusions? Such an overview would render a picture more or less along these lines:

Most women who have been circumcised seem to have gratifying sexual lives. ${ }^{8}$ Some women testify that circumcision had negative effects on their sexual well-being, ${ }^{9}$ and some opt for reconstructive genital surgery. ${ }^{10}$ Most men who have been circumcised seem to 
have gratifying sexual lives. ${ }^{11}$ Some men testify that circumcision had negative effects on their sexual well-being, ${ }^{12}$ and some opt for reconstructive genital surgery. ${ }^{13}$

Effects on sexual pleasure have been one of many themes discussed in relation to circumcision practices - it is a given consequence of the fact that genitalia play a central role in sexual activities. To arrive, however, at the conclusion that the state of the genitalia determines the quality of sexual activities or experiences is probably a mistake. Yet, it is precisely this fallacy that characterizes many academic contributions to the field.

In discussions about sexuality in relation to circumcision, one often finds a kind of lip service, where it is declared that sexuality is multifaceted: 'We recognize that sexual pleasure and satisfaction are multidimensional, depending, for example, also on affection and the time the partner takes to please the woman. However, the physiological viewpoint...' (Berg and Denison 2012, 50). Few authors discuss, in depth, the implications of a sexual-pleasure research approach that moves beyond the state of the genitalia (among the exceptions are Obermeyer 2005 and Esho et al. 2010).

Sexual scripting theory, introduced by the social scientists John H. Gagnon and William Simon in the 1970s, highlights the social dimensions of lived sexuality (e.g. Gagnon and Simon 1973). This framework, which demonstrates how sexuality is embedded in social and cultural contexts and how people learn how to enact their sexuality in relation to socially and culturally based norms, may be helpful in understanding how radically differently we construct, for example, the male and female sexualities. Two quotes from the literature on sexuality in groups where most of the girls and women are circumcised, Sudan and Kikuyu in Kenya, can serve as illustration of sexual scripting:

Custom decrees that a Sudanese woman remain totally passive during the sex act. She must act like a 'block of wood' and participate in no way whatsoever. Sudanese men confirm that in nearly all cases she does just that. Sexual pleasure is considered to be entirely a male prerogative, and if it is felt by women, it is felt in secret. Nearly all women interviewed reported that showing sexual interest and pleasure openly is 'extremely shameful.' [...] Sexually, the woman must exhibit an unnatural immobility. She is not required to be sexually active, 'like an animal.' Only passive behaviour will enable her to fulfill the demand for modesty imposed on her. If the woman has an orgasm, she tries to not show it, and if she is unable to control her reaction, she denies that it was brought on by sexual ecstasy. (Lightfoot-Klein 1989, 89)

Ssenga [father's sister] teaches the girl specific utterances and techniques appropriate during an intercourse. Traditionally, women are taught to not only desire sex but to also lead an active sex life. A woman is expected to reach orgasm several times before the man and respond throughout intercourse with vigorous body movement. A man is evaluated by women according to the length of time coitus is maintained before his orgasm (about thirty minutes is typical). A too-rapid male ejaculation is likely to evoke female anger and comparison with, for example, a 'hen' (enkoko) who, of course, has rapid coitus. A second erection soon after orgasm is also expected of men. (Kilbride and Kilbride 1990, in Njambi 2004, 297)

In the Berg et al. meta-analysis, we are told that no significant difference between cut and uncut women has been found 'with respect to whether they initiated sex' $(2012,48)$. One wonders: is it not more reasonable to believe that variation has more to do with culture-based sexual scripts than with whether or not cutting of the genitals has taken place?

If one keeps this cultural variation in mind, the variables used in existing quantitative studies on sexual effects of female circumcision appear quite absurd. There is a reason to question what kind of information we have at hand when data are collected on 'frequency of intercourse' and comparisons are made between cut and uncut women. ${ }^{14}$ Concepts such as 'sexual desire', 'libido', 'sexual satisfaction' and 'sexual problems' are employed with little or no theorizing (see also Obermeyer 2005 for critical discussion). Is it even possible to quantitatively measure 'sexual outcome', and - if it were possible - how could such a concept be operationalized in a way that takes cultural variation into consideration?

Apart from methodological flaws like these, these studies build upon faulty theoretical assumptions about the role of genitalia in sexuality. Possibly, western researchers in this field are captivated by typically western constructions of sexuality, which tend to overemphasize the role of 
anatomy and physiology in framing and describing sexual activities. In the words of Australian sociologist Juliet Richters: 'as if having sex were a physiological process like digestion rather than a social interaction like having dinner' (2009, 232; see also Tiefer 2004).

I believe that it is a fallacy to see instantiations of anatomy and physiology as universal entities, as if only embedded in cultural contexts to be swiftly peeled off at investigating sexual pleasure in putatively objective ways (sexual pleasure as ahistorical and beyond culture, or beneath a cultural surface). Social and cultural dimensions are integral to lived sexuality. Findings from the emergent research field of the 'anthropology of sensations' demonstrate how sensations are culturally learned - to grow up in a certain society entails learning to 'read' one's body in specific ways: 'Sensory meaning is never a question of physiology; it is always mediated by culture, in the sense of the ways of life, language, ritual practices, beliefs and aesthetics of a group, community, or society' (Hinton et al. 2008). Sensation schemas will impact how we perceive bodily signals, whether we notice them at all, and what kind of meanings we ascribe to them. This is also true for sexual activities: we need to 'decode' bodily sensations and relate them to culturally and socially created erotic meanings in order to experience sexual pleasure (Cameron and Kulick 2003; Tiefer 2004).

Such complexity is difficult to capture in quantitative studies, as pointed out by Darby and Svoboda (2007: 310). The subjective experience, completely dependent upon cultural and social context, is difficult to measure:

Arguments about circumcision reveal something of the limitations of evidence-based medicine. They can tell us how many circumcisions are necessary to prevent one case of penile cancer (about 1000), but they cannot engage with the subjective experiences of the sexual body. (Richters 2009, 229)

My point here is that the current academic focus on the role of genitalia in understanding sexual pleasure is a dead end. While genitalia usually are central to sexual activity, ${ }^{15}$ and can be seen as a prerequisite for sexual intercourse, it is a misapprehension to see the state of them (cut or uncut) as determinative of the individual's experience of the sexual encounter. Consequently, ongoing debates on enhancing or detrimental effects of circumcision practices often miss the point, since they are based in too narrow a theoretical framework of sexual pleasure.

\section{Notes}

1. See e.g. Shweder (2002, 2013); Bell (2005); Darby and Svoboda (2007); Solomon and Noll (2007); DeLaet (2009); Fox and Thomson (2009); and Johnson (2010) for similar analyses.

2. When terms such as 'clitoridectomy' and 'amputation' are used, what is referred to is cutting of the external structures of the clitoris. This organ, however, stretches far into the body (O'Connell et al. 2005).

3. In a discussion where intersex surgery is juxtaposed with female circumcision, the American law scholars Nancy Ehrenreich and Mark Barr contend that 'intersex genital surgeries are medically unnecessary, are far more complicated than African genital cutting, and often have equally, if not more, serious physical and psychological consequences for their recipients' $(2005,74)$.

4. It is instructive to have a closer look at the actual raw data in the studies used to support the conclusions about statistically significant increased risk. The two studies showing that 'women with FGM/C experience significantly less sexual satisfaction' are Alsibiani and Rouzi (2010) and Thabet and Thabet (2003), described by Berg et al. as follows: 'the quality of the evidence was "very low"' (Berg et al. 2010, 44). Alsibiani and Rouzi used the instrument Female Sexual Function Index and found that circumcised women scored 2.1 points lower on a scale of possible range from 2 to 36. Osinowo and Taiwo (2003), another study of 'low quality' and yet included in the meta-analysis, used another instrument (Golombok-Rust Inventory of Sexual Satisfaction) where circumcised women scored 17.5 points lower on a scale with a range between 56 and 280. Also included in the evidence presented by Berg et al. is a study (also 'low quality') showing that $69.5 \%$ of the circumcised women reported sexual problems, while only $63.7 \%$ of the uncircumcised did so. Figures like these are the strongest evidence presented of the alleged detrimental effects of female genital cutting on sexuality.

5. Accessible from: http://www.who.int/publications/en/

6. The hypothesis behind the figures, showing increased risk of pain and sexual frustration among female partners, goes something like this: 'When a circumcised man moves in and out of a woman without "the gliding movement" caused by the foreskin, it can have a painful effect on the woman's mucous membrane. This could 
explain the pain and the tendency towards dryness that some women with circumcised men experience', says the Danish epidemiologist Morten Frisch in an interview (ScienceNordic 2011). Further, according to Frisch, the circumcised man has to work harder to reach an orgasm, due to the desensitised glans of the penis, and that can lead to a painful experience for the woman.

7. For an ongoing debate on the pros and cons of male circumcision, including the issue of sexual pleasure, see Svoboda and Van Howe (2013); Frisch et al. (2013); and the AAP Task Force on Circumcision (2013, American Academy of Pediatrics).

8. E.g. Obermeyer (2005); Berg et al. (2010).

9. E.g. Gruenbaum (2006).

10. E.g. Foldès et al. (2012).

11. E.g. Krieger et al. (2008).

12. E.g. Kim and Pang (2007).

13. E.g. Evans (2011).

14. Conferring with studies by Kinsey, showing the enormous variation in the US in the 1940s (among uncut women, if not men). A prominent in-group variation like this - among cut and uncut women alike - was also what was found in these studies (Berg et al. 2010).

15. Obviously, another central organ is the brain. The prevalence of sleep orgasms (or nocturnal orgasms) in men and women - in absence of tactile genital stimulation - demonstrates that sexual pleasure is not exclusively a matter of genital tissue.

\section{Notes on contributor}

Sara Johnsdotter Ph.D. (Social Anthropology, Lund University, 2002) is Professor in Medical Anthropology at the Department of Health and Society, Malmö University. Her research is concerned with genital modifications, particularly female circumcision. Since 1997 she has worked closely with gynaecologist Dr. Birgitta Essén on issues of sexuality and reproductive health in a migration context.

\section{References}

AAP Task Force on Circumcision. 2013. "Cultural Bias and Circumcision: The AAP Task Force on Circumcision Responds." Pediatrics 131: 801-804.

Alsibiani, S. A., and A. Rouzi. 2010. "Sexual Function in Women with Female Genital Mutilation.” Fertility and Sterility 93 (3): 722-724.

Ansell, J. S., and J. Rajfer. 1981. "A New and Simplified Method for Concealing the Hypertrophied Clitoris." Journal of Pediatric Surgery 16 (5): 681-684.

Bell, K. 2005. "Genital Cutting and Western Discourses on Sexuality." Medical Anthropology Quarterly 19 (2): $125-148$.

Berg, R., E. Denison and A. Fretheim. 2010. Psychological, Social and Sexual Consequences of Female Genital Mutilation/Cutting (FGM/C): A Systematic Review of Quantitative Studies. Oslo: Norwegian Knowledge Centre for the Health Services.

Berg, R. C., and E. Denison. 2012. "Does Female Genital Mutilation/Cutting (FGM/C) Affect Women's Sexual Functioning? A Systematic Review of the Sexual Consequences of FGM/C." Sexuality Research and Social Policy 9 (1): 4-56.

Braun, V. 2005. “In Search of (Better) Sexual Pleasure: Female Genital ‘Cosmetic' Surgery.” Sexualities 8 (4): 407-424.

Bronselaer, G. A, J. M. Schober, H. F. L. Meyer-Bahlburg, G. T’sjoen, R. Vlietinck, and P. B. Hoebeke. 2013. "Male Circumcision Decreases Penile Sensitivity as Measured in a Large Cohort." BJU International 111 (5): 820-827.

Cameron, D., and D. Kulick. 2003. Language and Sexuality. Cambridge: Cambridge University Press.

Darby, R., and J. S. Svoboda. 2007. "A Rose by Another Name? Rethinking the Similarities and Differences between Male and Female Genital Cutting.” Medical Anthropology Quarterly 21 (3): 301-323.

DeLaet, D. L. 2009. "Framing Male Circumcision as a Human Rights Issue? Contributions to the Debate over the Universality of Human Rights." Journal of Human Rights 8: 405-426.

Dustin, M. 2010. "Female Genital Mutilation/Cutting in the UK: Challenging the Inconsistencies." European Journal of Women's Studies 17 (1): 7-23.

Ehrenreich, N., and M. Barr. 2005. "Intersex Surgery, Female Genital Cutting, and the Selective Condemnation of 'Cultural Practices'.” Harvard Civil Rights - Civil Liberties Law Review 40 (1): 71-140. 
Elchalal, U., B. Ben-Ami, R. Gillis, and A. Brzezinski. 1997. "Ritualistic Female Genital Mutilation: Current Status and Future Outlook." Obstetrical and Gynecological Survey 52 (10): 643-651.

Elnashar, A.M., K. E. Ibrahim,M. M. El-Desoky, O.M. Ali, andM. E.M. Hassan. 2007. "Female Sexual Dysfunction in Lower Egypt.” British Journal of Obstetrics and Gynaecology 14 (2): 201-206.

Esho, T., P. Enzlin, S. Van Wolputte, and M. Temmerman. 2010. "Female Genital Cutting and Sexual Function: In Search of an Alternate Theoretical Model." African Identities 8 (3): 221-235.

Evans, M. 2011. “Circumcision in Boys and Girls: Why the Double Standard?” British Medical Journal 342: 442.

Foldès, P., B. Cuzin, and A. Andro. 2012. "Reconstructive Surgery After Female Genital Mutilation: A Prospective Cohort Study." The Lancet 380 (9837): 134-141.

Fox, M., and M. Thomson. 2009. "Foreskin is a Feminist Issue.” Australian Feminist Studies 24 (60): 195-210.

Frisch, M. 2012. “Author's Response to: Does Sexual Function Survey in Denmark Offer Any Support for Male Circumcision Having an Adverse Effect?” International Journal of Epidemiology 41 (1): 312-314.

Frisch, M., Y. Aigrain, V. Barauskas, R. Bjarnason, S.-A. Boddy, P. Czauderna, R. P. E. de Gier, et al. 2013. "Cultural Bias in the AAP's 2012 Technical Report and Policy Statement on Male Circumcision." Pediatrics 131: 796-800.

Frisch, M., M. Lindolm, and M. Grønbæk. 2011. "Male Circumcision and Sexual Function in Men and Women: A Survey-based, Cross-Sectional Study in Denmark." International Journal of Epidemiology 40: 1367-1381.

Gagnon, J., and W. Simon. 1973. Sexual Conduct: The Social Sources of Human Sexuality. Chicago: Aldine.

Gruenbaum, E. 2006. "Sexuality Issues in the Movement to Abolish Female Genital Cutting in Sudan." Medical Anthropology Quarterly 20 (1): 121-138.

Hinton, D. E., D. Howes, and L. J. Kirmayer. 2008. “Toward a Medical Anthropology of Sensations: Definitions and Research Agenda." Transcultural Psychiatry 45 (2): 142-162.

Hughes, I. A, C. Houk, S. F. Ahmed, P. A. Lee, LawsonWilkins Pediatric Endocrine Society (LWPES)/ European Society for Paediatric Endocrinology (ESPE) Consensus Group. 2006. "Consensus Statement on Management of Intersex Disorders.” Journal of Pediatric Urology 2: 148-162.

Johnsdotter, S., and B. Essén. 2010. "Genitals and Ethnicity: The Politics of Genital Modifications." Reproductive Health Matters 18 (35): 29-37.

Johnson, M. 2010. "Male Genital Mutilation: Beyond the Tolerable?" Ethnicities 10 (2): 181-207.

Karkazis, K. 2008. Fixing Sex: Intersex, Medical Authority, and Lived Experience. Durham: Duke University Press.

Kelly, B., and C. Foster. 2012. "Should Female Genital Cosmetic Surgery and Genital Piercing be Regarded Ethically and Legally as Female Genital Mutilation?” British Journal of Obstetrics and Gynaecology 119: 389-392.

Kim, D., and M.-G. Pang. 2007. "The Effect of Male Circumcision on Sexuality.” BJU International 99 (3): 619-622.

Krieger, J. N, S. D. Mehta, R. C. Bailey, K. Agot, J. O. Ndinya-Achola, and C. Parker. 2008. “Adult Male Circumcision: Effects on Sexual Function and Sexual Satisfaction in Kisumu, Kenya." The Journal of Sexual Medicine 5 (11): 2610-2622.

Lean, W. L., J. M. Hutson, and A.V. Deshpande. 2007. “Clitoryplasty: Past, Present and Future.” Pediatric Surgery International 23: 289-293.

Lightfoot-Klein, H. 1989. Prisoners of Ritual: An Odyssey into Female Genital Circumcision in Africa. New York: The Haworth Press.

Maharaj, N. R., A. Dhai, R. Wiersma, and J. Moodley. 2005. "Intersex Conditions in Children and Adolescents: Surgical, Ethical, and Legal Considerations.” Journal of Pediatric and Adolescent Gynecology 18 (6): 399 402.

Malmström, M. 2009. "Just Like Couscous: Gender, Agency and the Politics of Female Circumcision in Cairo." Doctoral dissertation, School of Global Studies, Göteborg University.

Morris, B. J., J. H. Waskett, and R. H. Gray. 2012. "Does Sexual Function Survey in Denmark Offer Any Support for Male Circumcision Having an Adverse Effect?” International Journal of Epidemiology 41 (1): 310-312.

Njambi, W. N. 2004. "Dualisms and Female Bodies in Representations of African Female Circumcision: A Feminist Critique." Feminist Theory 5 (3): 281-303.

Nour, N. M. 2012. "Using Facts toModerate the Message." The Hastings Center Report 42 (6): 30-31.

Obermeyer, C. M. 2005. "The Consequences of Female Circumcision for Health and Sexuality: An Update on the Evidence." Culture, Health \& Sexuality 7 (5): 443-461.

O'Connell H. E., K.V. Sanjeevan, and J. M. Hutson. 2005. "Anatomy of the Clitoris.” The Journal of Urology 174: 1189-1195.

Osinowo, H. O., and A. O. Taiwo. 2003. "Impact of Female GenitalMutilation on Sexual Functioning, Selfesteem and Marital Instability ofWomen in Ajegunle." Ife Psychologia 11 (1): 123-130. 
Renganathan, A., R. Cartwright, and L. Cardozo. 2009. "Gynecological Cosmetic Surgery.” Expert Review of Obstetrics \& Gynecology 4 (2): 101-04.

Richters, J. 2009. "Bodies, Pleasure and Displeasure.” Culture, Health \& Sexuality 11 (3): 225-236.

ScienceNordic. 2011. "Male Circumcision Leads to a Bad Sex Life.” Accessed May 2, 2013. http:// sciencenordic.com/male-circumcision-leads-bad-sex-life

Shweder, R. A. 2002. “'What about Female Genital Mutilation?' And Why Understanding Culture Matters in the First Place.” In Engaging Cultural Differences: The Multicultural Challenge in Liberal Democracies, edited by R. Shweder, M. Minow, and H. R. Markus. New York: Russell Sage Foundation.

Shweder, R. A. 2013. "The Goose and the Gander: The Genital Wars," manuscript available from Richard A. Shweder at this e-mail address: rshd@uchicago.edu

Solomon, L. M., and R. C. Noll. 2007. "Male Versus Female Genital Alteration: Differences in Legal, Medical, and Socioethical Responses." Gender Medicine 4 (2): 89-96.

Svoboda, J. S., and R. S. Van Howe. 2013. "Out of Step: Fatal Flaws in the Latest AAP Policy Report on Neonatal Circumcision.” Journal of Medical Ethics, published online March 18, 2013 [Epub ahead of print].

The Public Policy Advisory Network on Female Genital Surgeries in Africa. 2012. "Seven Things to Know About Female Genital Surgeries in Africa." The Hastings Center Report 42 (6): 19-27.

Tiefer, L. 2004. Sex Is Not a Natural Act and Other Essays. Oxford: Westview Press.

Toubia, N. 1994. "Female Circumcision as a Public Health Issue." New England Journal of Medicine 331: 712716.

Veale, D., and J. Daniels. 2012. "Cosmetic Clitoridectomy in a 33-year-old Woman.” Archives of Sexual Behavior 41: 725-730.

Wade, L. 2012. "The Function of Balance in US News Coverage of Uncontested Issues: The Case of Female Genital Cutting." Journalism 13 (7): 869-885.

WHO. 2012. "Female Genital Mutilation.” Accessed April 30, 2013. http://apps.who.int/iris/bitstream/ 10665/77428/1/WHO_RHR_12.41_eng.pdf

WHO, UNAIDS, and JHPIEGO. 2009. "Manual for Male Circumcision under Local Anaesthesia.” Accessed April 30, 2013. http://www.who.int/hiv/pub/malecircumcision/who_mc_local_anaesthesia.pdf

Woodhouse, C. R. J. 2004. “Intersex Surgery in the Adult.” BJU International 93 (suppl. 3): 57-65. 